\title{
Analisis Penyebab Kerusakan Mesin Produksi Kayu Lapis
}

\author{
Bramantiyo Eko Putro" ${ }^{* 1}$, Moch Yusup A Aziz \\ ${ }^{1,2}$ Program Studi Teknik Industri, Fakultas Teknik, Universitas Suryakancana \\ Jl. Pasir Gede Raya, Cianjur, 43216, Indonesia \\ Email: bramantiyo@unsur.ac.id ${ }^{1}$, yusufvespa16@gmail.com ${ }^{2}$
}

DOI: $10.20961 /$ performa.19.2.45381

\begin{abstract}
Abstrak
PT. Sama Al-Tanmiah merupakan perusahaan yang bergerak di bidang industri produksi kayu lapis setengah jadi. Bahan baku setengah jadi diproses lebih lanjut disesuaikan dengan kebutuhan pembeli, penyebab kerusakan karena mesin tidak terawat dan kualitas komponen menurun. Penelitian ini dilakukan untuk mengetahui asal penyebab kerusakan pada mesin produksi di perusahaan PT. Sama Al-Tanmiah. Pengambilan data yang diperoleh dengan cara wawancara, observasi dan meminta data sekunder selama 6 bulan produksi, untuk pengolahan data dengan menggunakan Fault Tree Analysis dan Failure Mode and Effect Analysis. Data-data yang didapat dari perusahaan masuk ke pengelolaan data tahap berikutnya akan dibentuk analisis gambar pohon kesalahan dengan menggunakan Microsoft Visio dan pemberian bobot ke tiga mesin produksi dengan menggunakan Microsoft Excel. Hasil dari peneliti mendapatkan akar pohon kesalahan dan nilai RPN dengan pembobotan kerusakan mesin. Perbaikan manajemen dan standar operasional prosedur (SOP).
\end{abstract}

Kata kunci: Kayu Lapis, Kerusakan mesin, FTA, dan FMEA

\begin{abstract}
PT. Sama Al-Tanmiah is a company engaged in the semi-finished plywood production industry. Semifinished raw materials are further processed according to the needs of the buyer, the cause of damage is due to poor maintenance and deteriorating component quality. This research was conducted to determine the origin of the causes of damage to the production machine at PT. Same Al-Tanmiah. Retrieval of data obtained by means of interviews, observation and requesting secondary data for 6 months of production, for data processing using Fault Tree Analysis and Failure Mode and Effect Analysis. The data obtained from the company enters into data management. The next stage will be a fault tree image analysis using Microsoft Visio and weighting to the three production machines using Microsoft Excel. The results of the researchers obtained the root of the fault tree and the value of the RPN with weighted machine damage. Improvement of management and standard operating procedures (SOP).
\end{abstract}

Keywords: Plywood, Enginee Failure, FTA, and FMEA

\section{Pendahuluan}

Indonesia merupakan negara kepulauan yang mempunyai banyak potensi, diantaranya adalah hutan Indonesia yang ditumbuhi dengan berbagai macam jenis pohon. Hal ini bisa menjadi salah satu pendapatan negara dengan mengolah pohon menjadi berbagai macam produk seperti kayu lapis. Kementerian Lingkungan Hidup dan Kehutanan menyatakan saat ini sumber bahan baku untuk industri di Indonesia, berasal dari kayu rakyat dengan besaran sumbangan 14,3\% dari total 8,25 juta $\mathrm{m}^{3}$ (Dini 2019). Kebutuhan kayu di Indonesia setiap tahun meningkat. Direktur Bina Usaha Hutan Alam Kementerian Kehutanan, menuturkan tegakan yang siap panen di areal hak pengusaha hutan (HPH) mencapai 14 juta $\mathrm{m}^{3}$ pada tahun 2013 (Noviani 2013), dan diperkirakan kebutuhan kayu nasional Indonesia mencapai lebih dari 60 juta $\mathrm{m}^{3}$. Lima puluh persen dari kebutuhan kayu tersebut digunakan sebagai bahan baku industri kayu lapis atau plywood. Peningkatan setiap tahun diperkirakan sekitar $80 \%$ konsumsi bahan baku kayu dalam negeri yang digunakan untuk kebutuhan bahan baku industri dan kebutuhan peralatan rumah tangga atau kebutuhan pembangunan rumah yang pada dasarnya kayu adalah 20\% (Suwandi, 2015)

${ }^{*}$ Corresponding author 
Pelaku usaha kayu olahan menilai pada 2018 volume produksi kayu olahan akan naik 10\% dari total capaian sepanjang 2019. Purwadi memproyeksikan produksi kayu bulat di Hutan Tanaman Indonesia (HTI) tahun ini akan naik 10\% dibandingkan dengan realisasi produksi tahun lalu yang mencapai 40,13 juta $\mathrm{m}^{3}$. Produksi kayu tersebut hingga saat ini dipenuhi oleh 294 kelompok petani hutan yang terdiri dari 106 ribu orang anggota dengan luas area sekitar satu juta hektare (ha) (Baqiroh 2019). Luas area bahan baku kayu tersebut bisa diperkirakan cukup untuk memenuhi kebutuhan komersial rumah tangga dan perusahaan industri kayu, dari kebutuhan kayu tersebut digunakan sebagai bahan baku industri kayu lapis.

PT. Sama Al-Tanmiah merupakan salah satu perusahaan manufaktur yang memproduksi kayu lapis setengah jadi. Perusahaan yang terletak di kabupaten Cianjur, Desa Bobojong, Kecamatan Mande. Produk utama kayu lapis PT. Sama Al-Tanmiah merupakan produk setengah jadi yang dipotong sesuai standar dan siap dikirim ke produsen di Jawa Tengah untuk diproses lebih lanjut menjadi tripleks. Bahan baku yang digunakan untuk produksi kayu lapis di perusahaan tersebut menggunakan beberapa jenis pohon diantaranya meranti, albasia, dan mahoni

Proses produksi menggunakan 3 mesin, yang pertama adalah mesin kupas kulit (The Barker) yaitu dimana kayu gelondongan tersebut diratakan agar kayu tersebut rata sejajar, yang ke 2 adalah mesin ukur (Spinlees) tujuannya yaitu dimana kayu yang sudah diserut langsung masuk ke mesin ukur dan sudah diukur ketebalannya dan selanjutnya mesin potong (Autoclipper) dalam mesin ini adalah pemotongan kayu yang sudah diserut dan sesuai ukuran kebutuhan yang akan dikirim ke konsumen.

Penelitian ini bertujuan untuk mengidentifikasi faktor-faktor penyebabnya kerusakan mesin produksi dan kerusakan yang paling sering terjadi pada mesin produksi kayu lapis. Kerusakan mesin pada PT. Sama Al-Tanmiah ini kerusakan biasanya terjadi pada mata pisau, putus rantai, pecah dudukan dinamo, pecah bearing, pecah selang hidrolik, keausan bagian rool, bearing, gear, dan beberapa kerusakan yang telah diuraikan seringnya terjadi kerusakan pada semua mesin produksi. Kerusakan tersebut menyebabkan proses produksi kayu lapis terhenti sampai beberapa jam atau berhenti produksi menyeluruh. Hal ini dikarenakan sparepart yang harus diganti secara keseluruhan dengan hasil observasi perusahaan hanya mengganti bagian mesin sementara.

\section{Metode Penelitian}

Penelitian ini menggunakan dua metode Fault Tree Analysis dan Failure Mode and Effect Analysis, dari kedua metode tersebut untuk mengetahui dan mengurangi kegagalan dan hambatan dalam produksi atau terhambat, dan mengidentifikasi kerusakan mesin produksi. Analisis pohon kesalahan adalah teknik yang digunakan untuk menentukan risiko menyebabkan kesalahan. Metode ini dilakukan dengan cara (top-down) (Fauzi dan Aulawi, 2016). Metode pertama mengasumsikan terjadinya peristiwa atas atau peristiwa puncak yang mengarah pada kegagalan atau kerugian, dan kemudian merinci penyebab acara puncak ke kegagalan dasar atau (root cause). Failure Mode and Effect Analysis (FMEA) adalah sebuah teknik menganalisa yang mengombinasikan antara teknologi dan pengalaman dari orang dalam mengidentifikasi penyebab kegagalan dari produk atau proses dan perencanaan untuk penghilangan penyebab kegagalannya (Badariah dkk., 2012) Pembuatan FMEA bertujuan untuk mengidentifikasi dan menilai risikorisiko yang berhubungan dengan potensi kegagalan (Iswanto dkk., 2013). Flowchart tahapan penelitian dapat dilihat pada Gambar 1 .

Langkah-langkah dari penelitian Fault Tree Analysis (FTA) pada penelitian ini adalah sebagai berikut (Hanif dkk., 2015):

1. Menuliskan kerusakan apa saja yang terjadi ketika proses produksi sedang berjalan.

2. Mengumpulkan nama-nama setiap kerusakan suku cadang pada mesin produksi.

3. Membuat akar pohon dari kerusakan yang sering terjadi.

Tahap selanjutnya yaitu penggunaan metode Failure Mode Effect Analysic (FMEA) adalah sebagai berikut (Puspitasari dan Martanto, 2014): 
1. Menentukan proses yang mempunyai risiko kerusakan yang tinggi pada setiap mesin.

2. Menyusun diagram proses.

3. Menentukan prioritas failure modes penetapan berdasarkan Risk priority number (RPN). Langkah penentuan RPN yaitu dengan skala kerusakan dari rating 1 sampai 10.

4. Mengidentifikasi asal penyebab masalah dari failure modes.

5. Analisis dan pengujian proses

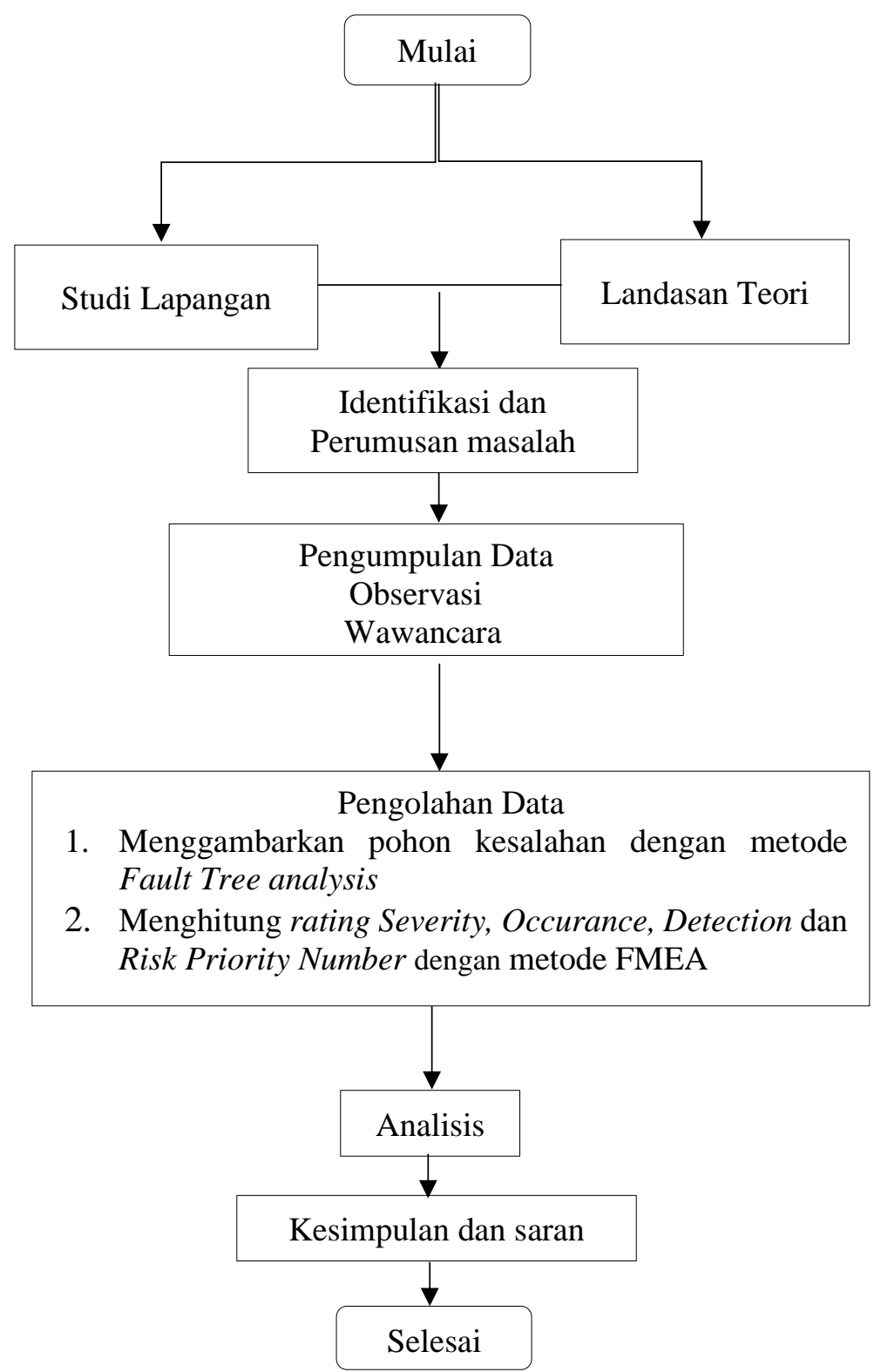

Gambar 1. Flowchart Penelitian 


\section{Hasil dan Pembahasan}

Hasil penjabaran pohon kesalahan yang terjadi pada awal proses produksi dan hasil akhir produksi dan bisa dilihat pada beberapa gambar.

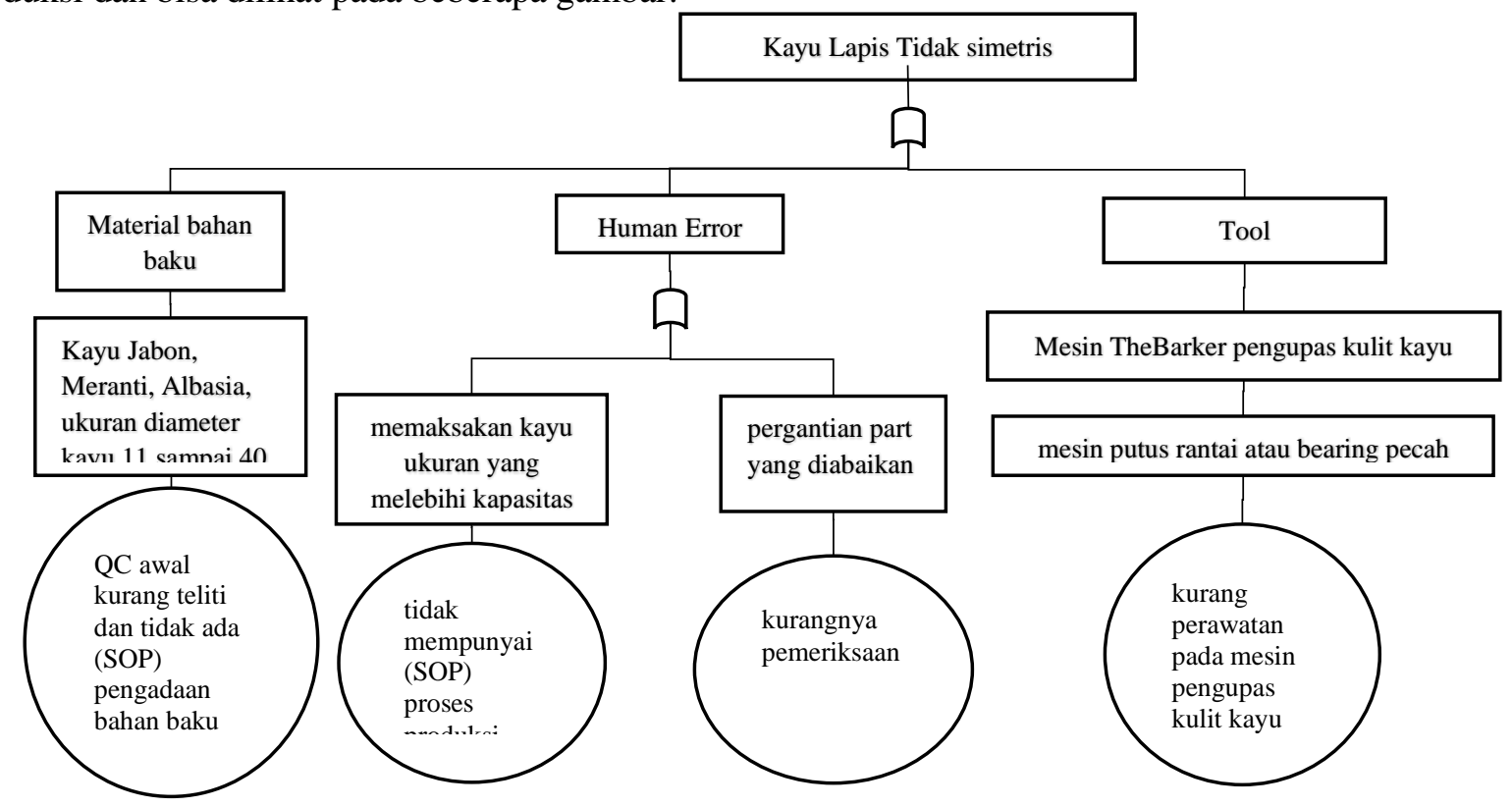

Gambar 2. Pohon Kesalahan Proses Pengupasan kulit kayu (The Barker)

Berdasarkan Gambar 2 ada 3 penyebab adalah faktor yaitu bahan baku, kesalahan manusia dan mesin. Material bahan baku memakai dengan tingkat kekerasan kayu yang berbeda-beda. Penyebab kedua adalah kesalahan dalam memasukkan kayu gelondong dengan ukuran yang terlalu besar, serta dipaksakan masuk ke mesin pengupas kulit kayu. Hal tersebut dapat menyebabkan mesin rusak dengan pemeriksaan mesin yang kurang perawatan dan pergantian part yang diabaikan. Ketiga yaitu disebabkan oleh tools atau mesin yang digunakan dalam proses pengupasan suatu masalah pada mesin tersebut dan mengakibatkan terjadinya kerusakan pada proses pengupasan kulit kayu untuk proses ke tahap selanjutnya.

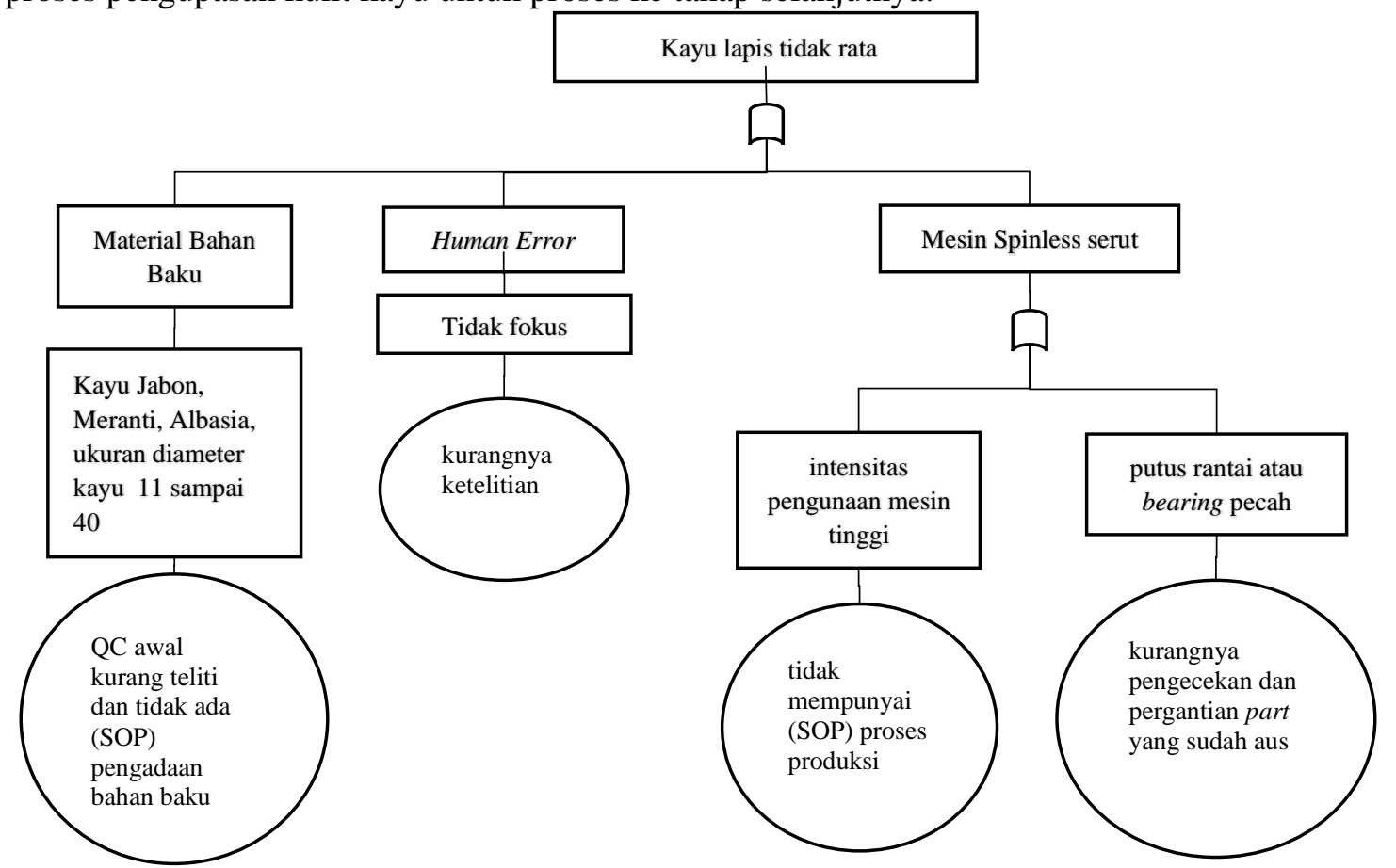

Gambar 3. Pohon Kesalahan Proses penggilingan/serut kayu (Spinless) 
Gambar 3 menunjukkan penyebab kerusakan mesin bearing aus, putus rantai dan hasil produksi kayu lapis tidak sesuai ukuran yang diharapkan. Penyebab kerusakan dibagi menjadi tiga bagian yaitu bahan baku material kayu, human error dan mesin yang digunakan. Pertama adalah bahan baku kayu yang digunakan, Kedua human error dimana penyebab kerusakan ini merupakan pekerja yang tidak fokus. Hal ini disebabkan kurangnya ketelitian dimana bahan kayu dengan ukuran besar dipaksakan masuk ke mesin serut. Ketiga adalah penggunaan mesin serut dengan intensitas yang tinggi untuk menggiling/serut kayu gelondong. Proses pemaksaan tersebut mengakibatkan bearing aus hasil penyerutan tidak merata atau rantai putus alhasil produksi akan terhenti pada mesin tersebut dan proses mesin selanjutnya juga akan terhenti, kesalahan kurangnya perawatan dan pergantian part yang sudah aus.

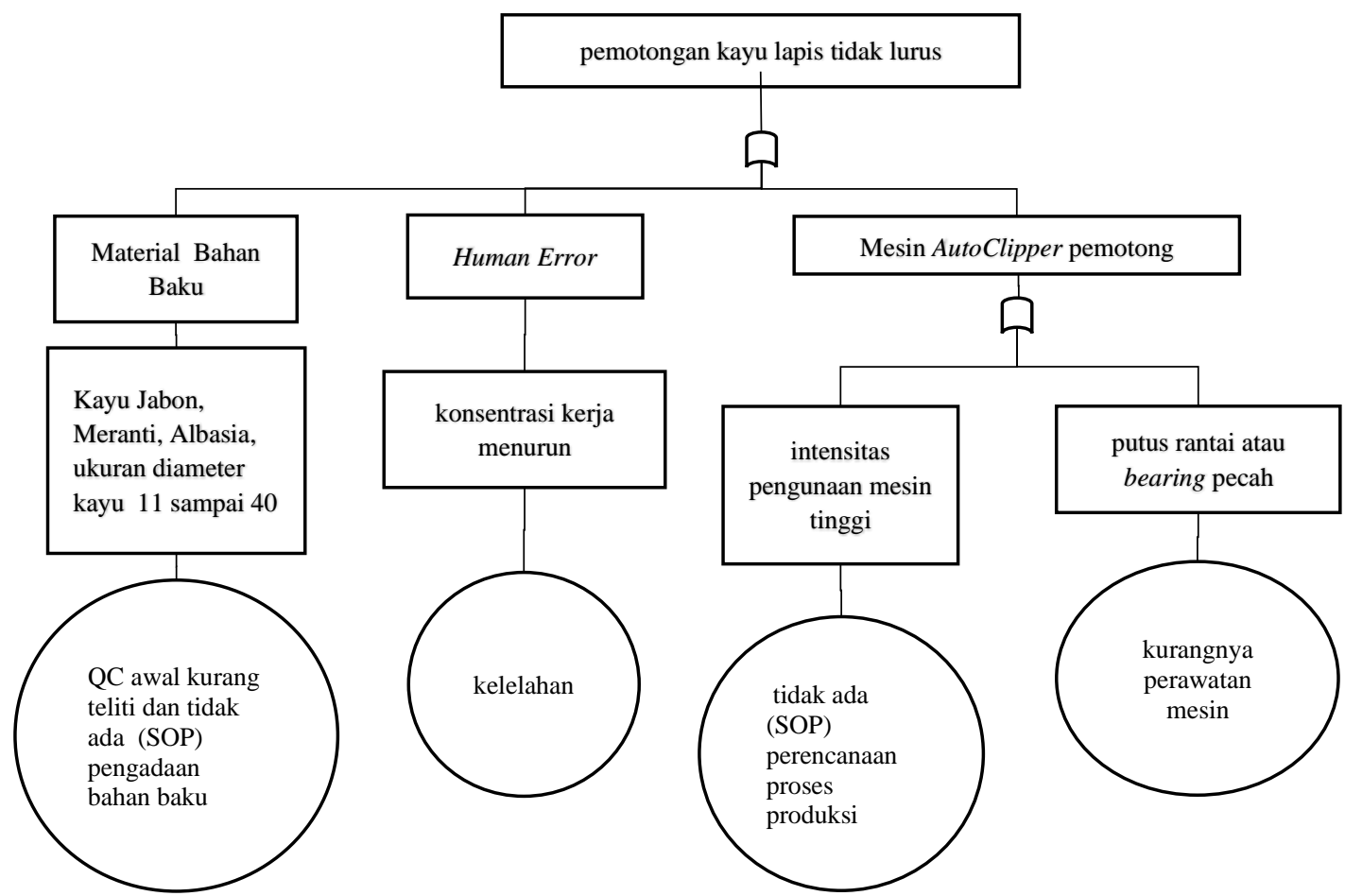

Gambar 4. Pohon Kesalahan Proses pemotongan kayu lapis (Autoclipper)

Gambar 4 menunjukkan terdapat tiga faktor penyebab kerusakan yaitu bahan baku kayu, human error dan mesin. Penggunaan bahan baku kayu juga berpengaruh pada proses produksi karena setiap kayu berbeda beda kekerasannya. Kerusakan mesin pemotong yang disebabkan oleh faktor manusia karena kelelahan dalam bekerja dan menurunnya konsistensi saat bekerja. Kedua yaitu dari mesin pemotong itu sendiri dimana terjadi kerusakan part yang bermasalah. Hal ini dikarenakan kurangnya perawatan terhadap mesin pemotong lembaran kayu lapis dan kerusakan putus rantai yang menyebabkan proses pemotongan terhenti dan tidak bisa dilanjutkan. Bearing aus yang menyebabkan hasil pemotongan tidak sesuai yang diinginkan.

Penyebab kerusakan bersumber pada menurunnya daya tahan part yang dipakai akibat kurangnya perawatan pada ketiga mesin tersebut dan kurangnya ketelitian. Hal tersebut berdampak ketika ada komponen yang rusak maka produksi akan terhenti keseluruhan dimana mesin ke 1 terdapat komponen part yang rusak. Berdasarkan dari observasi dapat diketahui perusahaan tersebut yaitu sistem Make To Order atau membuat sesuai pesanan dari pembeli. Penyebab kerusakan mesin adanya kesalahan ketika pembelian pada bahan baku kayu gelondong ke pemborong, dimana bahan baku tersebut dikirim ke perusahaan dengan ukuran diameter yang bervariasi. Kurangnya ketelitian pada proses pemesanan agar ukuran diameter bahan baku kayu gelondong tersebut tidak melebihi kapasitas ukuran untuk mesin produksi yang bilamana dipaksakan akan mengalami kerusakan pada mesin produksi. 
Berdasarkan dari hasil pengolahan dan pembobotan nilai RPN pada proses pengupas kulit (The Barker) mendapatkan nilai kerusakan tertinggi setelah dianalisis dengan metode FTA dan FMEA dan bisa mengetahui masalah ketika terjadi yaitu dilakukan perawatan, berikut saran perawatan untuk ke tiga mesin produksi yang dapat dilihat pada Tabel 1 dan Tabel 2.

Tabel 1. Ringkasan poin FMEA

\begin{tabular}{|c|c|c|c|c|}
\hline \multirow[t]{2}{*}{ No } & \multirow{2}{*}{$\begin{array}{l}\text { Deskripsi proses } \\
\text { Mesin Produksi }\end{array}$} & \multirow[t]{2}{*}{ Mode Kerusakan } & \multicolumn{2}{|c|}{ Potensi Efek kerusakan } \\
\hline & & & Proses Berikutnya & Performansi Produk \\
\hline 1 & $\begin{array}{l}\text { Mesin Pengupas } \\
\text { kayu gelondong } \\
\text { (The Barker) }\end{array}$ & $\begin{array}{l}\text { bearing aus, } \\
\text { pengupasan kayu } \\
\text { gelondong tidak } \\
\text { sempurna }\end{array}$ & $\begin{array}{l}\text { proses penggilingan kayu } \\
\text { tidak sesuai ukuran yang telah } \\
\text { di tetapkan }\end{array}$ & $\begin{array}{l}\text { kayu lapis yang tidak bisa } \\
\text { digunakan dengan ukuran } \\
\text { yang tidak sama }\end{array}$ \\
\hline 2 & $\begin{array}{l}\text { Mesin penggiling } \\
\text { kayu gelondong } \\
\text { (Spinless) }\end{array}$ & $\begin{array}{l}\text { aus bearing atau } \\
\text { putus rantai } \\
\text { penyerutan tidak } \\
\text { merata }\end{array}$ & $\begin{array}{l}\text { proses penyerutan tidak bisa } \\
\text { berjalan atau tertunda }\end{array}$ & $\begin{array}{l}\text { kayu lapis tidak sesuai ukuran } \\
\text { ketebalan }\end{array}$ \\
\hline 3 & $\begin{array}{l}\text { Mesin pemotong } \\
\text { lembaran kayu } \\
\text { (Auto Clipper) }\end{array}$ & $\begin{array}{l}\text { putus rantai, } \\
\text { bearing aus } \\
\text { pemotongan tidak } \\
\text { simetris }\end{array}$ & $\begin{array}{l}\text { proses pemotongan masuk ke } \\
\text { pengecekan lapisan untuk } \\
\text { dikemas dengan catatan } \\
\text { ukuran telah sesuai yang telah } \\
\text { di inginkan }\end{array}$ & $\begin{array}{l}\text { pemotongan menjadi tidak } \\
\text { rata, dan mengakibatkan hasil } \\
\text { kayu lapis menjadi miring }\end{array}$ \\
\hline
\end{tabular}

Tabel 2. Lanjutan Ringkasan poin FMEA

\begin{tabular}{|c|c|c|c|c|c|}
\hline $\mathrm{S}$ & Potensi penyebab kerusakan & $\mathrm{O}$ & Proses control saat ini & $\mathrm{D}$ & RPN \\
\hline 8 & $\begin{array}{l}\text { Human error: kesalahan dengan } \\
\text { cara memaksakan mesin } \\
\text { bekerja. Tools : mesin rusak } \\
\text { dengan pemakaian yang tinggi } \\
\text { dan bearing cepat aus atau } \\
\text { putus rantai }\end{array}$ & 8 & $\begin{array}{l}\text { pengawasan untuk pekerja dan mesin jika } \\
\text { mengalami kerusakan atau aus pada part mesin } \\
\text { harus diperiksa }\end{array}$ & 7 & 448 \\
\hline 7 & $\begin{array}{l}\text { kesalahan hasil penyerutan tidak } \\
\text { rata dikarenakan mesin } \\
\text { bermasalah dan pekerja } \\
\text { memaksakan untuk tetap } \\
\text { melanjutkan produksi }\end{array}$ & 8 & $\begin{array}{l}\text { pemeriksaan bagian ini harus di periksa supaya } \\
\text { pada penyerutan kayu agar sesuai dengan ukuran } \\
\text { yang diharapkan dan tidak melenceng }\end{array}$ & 7 & 329 \\
\hline 8 & $\begin{array}{l}\text { kerusakan mesin dengan } \\
\text { keadaan aus yang dapat } \\
\text { menyebabkan pemotongan } \\
\text { menjadi miring, dan } \\
\text { memaksakan mesin bisa } \\
\text { merusak rantai terputus }\end{array}$ & 6 & $\begin{array}{l}\text { proses pemeriksaan dimana bagian mesin ini } \\
\text { adalah pada saat pemotongan tidak simetris atau } \\
\text { miring, diharapkan ketika pemakaian mesin yang } \\
\text { tinggi dengan adanya pengecekan setiap berkala }\end{array}$ & 7 & 336 \\
\hline
\end{tabular}

Tabel 3. Susunan risk priority number (RPN)

\begin{tabular}{cclcccc}
\hline No & Mesin & \multicolumn{1}{c}{ Model kerusakan } & S & O D & RPN \\
\hline 1 & Kupas kulit kayu & $\begin{array}{l}\text { bearing aus, akibat dipaksakan dengan ukuran } \\
\text { kayu yang besar. }\end{array}$ & 8 & 8 & 7 & 448 \\
\hline 2 & $\begin{array}{c}\text { Pemotong } \\
\text { lembaran kayu }\end{array}$ & $\begin{array}{l}\text { bearing aus, pemotongan kayu tidak } \\
\text { simetris/miring }\end{array}$ & 8 & 6 & 7 & 336 \\
\hline 3 & $\begin{array}{l}\text { Penggiling } \\
\text { kayu/serut }\end{array}$ & $\begin{array}{l}\text { putus rantai, proses produksi tertunda, dan } \\
\text { bearing aus, penyerutan tidak sesuai dengan } \\
\text { ukuran }\end{array}$ & 7 & 8 & 7 & 329 \\
\hline
\end{tabular}




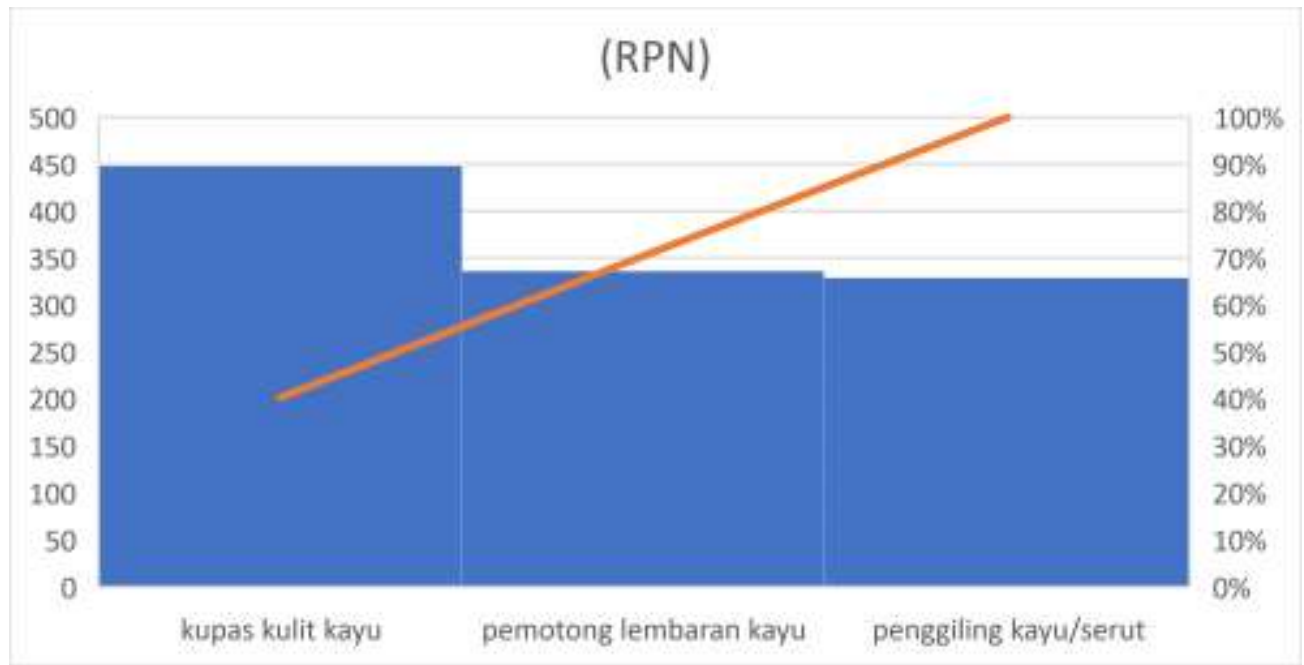

Gambar 5. Diagram pareto kayu lapis berdasarkan (RPN)

Berdasarkan Tabel 3 dan Gambar 5 didapatkan proses pengupas kulit kayu gelondong, penggiling kayu gelondong, dan pemotong kayu lapis dampak yang ditimbulkan dari 3 proses ini sangat mempengaruhi kerusakan mesin. Jumlah kerusakan yang sering timbul dengan intensitas pemakaian mesin yang tinggi dengan kurangnya perawatan mesin produksi dan kerusakan yang melebihi toleransi dari perusahaan tersebut. Hal ini haruslah mengadakan perawatan dan perbaikan asal penyebab yang terjadi dan sudah dicermati sesuai metode FTA dan FMEA.

\section{Simpulan}

Bagian simpulan harus dapat menjawab tujuan penelitian. Jelaskan hasil-hasil penting yang didapatkan yang terkait dengan tujuan penelitian. Selain itu, bagian ini juga menjelaskan keterbatasan penelitian yang dilakukan dan gagasan penelitian berikutnya. Bagian ini ditulis dalam bentuk paragraf dan tidak diperbolehkan ditulis dalam poin-poin.

Berdasarkan hasil dari penelitian ini yang telah dilakukan pada mesin produksi kayu lapis di PT. Sama Al-Tanmiah, didapatkan kesimpulan yaitu sebagai berikut:

1. Beberapa faktor yang muncul yaitu faktor bahan baku kayu gelondong, manusia dan mesin. Penyebab pada faktor mesin adalah kurangnya perawatan mesin, intensitas penggunaan mesin yang sangat tinggi, dan kekuatan komponen mesin menurun efek dari pemakaian tersebut. Faktor bahan baku disebabkan quality control awal kurang teliti dan tidak ada standar operasi prosedur (SOP) pengadaan bahan baku. Faktor kesalahan manusia (human error) diantaranya adalah tidak adanya standar operasi prosedur (SOP), faktor kelelahan, dan kurangnya ketelitian.

2. Kerusakan yang paling sering muncul yaitu pada mesin kupas kulit (The Barker) dengan nilai RPN sebesar 448. Kerusakan yang sering terjadi adalah kerusakan komponen bearing aus, dan putus rantai.

\section{Daftar Pustaka}

Badariah, Nurlailah, Dadang Surjasa, Yuda Trinugraha, and Jurusan Teknik Industri. 2012. "ANALISA SUPPLY CHAIN RISK MANAGEMENT BERDASARKAN METODE FAILURE MODE AND EFFECTS ANALYSIS (FMEA)." JURNAL TEKNIK INDUSTRI 2(2): 110-18.

Baqiroh, Nur Faizah Al Bahriyatul. 2019. "Produksi Kayu Olahan Diprediksi Naik 10\% Ekonomi Bisnis.Com.” Bisnis: 3-4.

Dini. 2019. "Pasok Kebutuhan Industri Kayu, 140 Kelompok Petani Hutan Difasilitasi : Okezone Economy." Okezone: 1-2.

Fauzi, Yadi Ahmad, and Hilmi Aulawi. 2016. "ANALISIS PENGENDALIAN KUALITAS 
PRODUK PECI JENIS OVERSET YANG CACAT DI PD. PANDUAN ILLAHI DENGAN MENGGUNAKAN METODE FAULT TREE ANALYSIS (FTA) DAN METODE FAILURE MODE AND EFFECT ANALYSIS (FMEA)"." Jurnal Kalibrasi 14(1): 29-34.

Hanif, Richma Yulinda, Hendang Setyo Rukmi, and Susy Susanty. 2015. "PERBAIKAN KUALITAS PRODUK KERATON LUXURY DI PT. X DENGAN MENGGUNAKAN METODE FAILURE MODE and EFFECT ANALYSIS (FMEA) Dan FAULT TREE ANALYSIS (FTA) * RICHMA YULINDA HANIF, HENDANG SETYO RUKMI, SUSY SUSANTY." Jurnal Online Institut Teknologi Nasional Juli 3(3): 137-47.

Iswanto, Adi, A Jabbar, M Rambe, and Elisabeth Ginting. 2013. "APLIKASI METODE TAGUCHI ANALYSIS DAN FAILURE MODE AND EFFECT ANALYSIS (FMEA) UNTUK PERBAIKAN KUALITAS PRODUK DI PT. XYZ." Jurnal Teknik Industri FT USU 2(2): 13-18.

Noviani, Ana. 2013. "Kebutuhan Bahan Baku Wood Working Naik 10\% Per Tahun - Ekonomi Bisnis.Com." Bisnis: 1-2.

Puspitasari, Nia Budi, and Arif Martanto. 2014. "PENGGUNAAN FMEA DALAM MENGIDENTIFIKASI RESIKO KEGAGALAN PROSES PRODUKSI SARUNG ATM (ALAT TENUN MESIN) (STUDI KASUS PT. ASAPUTEX JAYA TEGAL).”J@TI UNDIP : JURNAL TEKNIK INDUSTRI 9(2): 93-98. 